Supplementary material for

\title{
Large-wavelength late Miocene thrusting in the North Alpine foreland: Implications for late orogenic processes
}

\author{
Samuel Mock ${ }^{1}$, Christoph von Hagke ${ }^{2}$, Fritz Schlunegger ${ }^{1}$, István Dunkl ${ }^{3}$ and Marco \\ Herwegh $^{1}$ \\ ${ }^{1}$ Institute of Geological Sciences, University of Bern, Baltzerstrasse 1+3, 3012 Bern, Switzerland \\ ${ }^{2}$ Institute of Geology and Palaentology, RWTH Aachen University, Wüllnerstrasse 2, 52056 Aachen, Germany \\ ${ }^{3}$ Geoscience Center, Sedimentology and Environmental Geology, University of Göttingen Goldschmidtstrasse 3, \\ 37077 Göttingen, Germany \\ *Corresponding author: Samuel Mock (samuel.mock@geo.unibe.ch)
}

\section{Contents of this file}

Text S1

\section{Text S1}

\section{Apatite separation and picking}

\section{Electrodynamic disaggregation (selFrag)}

To release the apatite crystals from the rock samples, we used the electrodynamic disaggregation technique (selFrag). This method exposes the rock specimen to a high voltage pulse and fractures it along its grain boundaries. As opposed to separation using a jaw crusher, this method is less time consuming and the rock is disintegrated along the grain boundaries (Giese et al., 2010). This ensures individual grains are less prone to damaging during processing.

To prepare the samples for electrodynamic disaggregation, they had to be crushed into fist-sized pieces by hand using a hammer. This was necessary due to the limiting dimensions of the processing vessel of the selFrag. For releasing the individual grains, we applied a frequency of $3 \mathrm{~Hz}$ and electric potentials of $130-150 \mathrm{kV}$, depending on the hardness of the rock. For every sample, the electrode distance was incrementally reduced in $5 \mathrm{~mm}$ steps from a maximum of $40 \mathrm{~mm}$ to a minimum of $15 \mathrm{~mm}$. Per step, a minimum of 20 pulses was applied to ensure full release of the individual grains. It has been shown that the influence of diffusive loss of ${ }^{4} \mathrm{He}$ due to the plasma channel hitting the apatite crystal is negligible, and (U-Th$\mathrm{Sm}) / \mathrm{He}(\mathrm{AHe})$ ages from samples separated with electrodynamic disaggregation are indistinguishable from AHe ages measured on apatites released with mechanical techniques (Giese et al., 2010).

\section{Apatite concentration}

Apatite crystals were concentrated using standard rock separation techniques. First, the grain size fraction of $64-250 \mu \mathrm{m}$, which is suitable for AHe dating, was separated using disposable sieving meshes. To remove magnetic minerals from the sieved sample fraction, we used a Frantz magnetic separator at $0.5 \mathrm{~A}$ and $1.2 \mathrm{~A}$. To concentrate apatite from the 
remaining grains, we used lithium-based tungstate (LST) as heavy liquid for density separation of the heavy minerals. On average, we had to process ca. $100 \mathrm{~g}$ of sample material to acquire enough heavy minerals. The heavy mineral fraction has been thoroughly rinsed with deionized water and then dried at $30^{\circ} \mathrm{C}$.

\section{Apatite picking}

Apatites have been hand-picked under a binocular and checked for inclusions and imperfections under an optical microscope with cross-polarized light. Wherever possible, we selected euhedral, intact, and inclusion free grains with a minimum width of $60 \mu \mathrm{m}$. However, as the grains are detrital, partly grains with rough surfaces or tiny fluid inclusions had to be picked. This may result in larger error bars or even grain ages that do not yield a geologically meaningful age. These ages were excluded (see main text and Table S1 in the supporting information).

\section{References}

Giese, J., Seward, D., Stuart, F.M., Wüthrich, E., Gnos, E., Kurz, D., Eggenberger, U., and Schreurs, G., 2010, Electrodynamic Disaggregation: Does it Affect Apatite Fission-Track and (U-Th)/He Analyses? Geostandards and Geoanalytical Research, v. 34, p. 39-48, doi: 10.1111/j.1751-908X.2009.00013.x. 